\title{
Farelo de manga na dieta de cordeiros em confinamento
}

\author{
[Mango meal in diets of feedlot lambs] \\ A.S.L. Aragão ${ }^{1}$, L.G.R. Pereira ${ }^{2}$, M.L. Chizzotti ${ }^{3}$, T.V. Voltolini ${ }^{2}$ J.A.G. Azevêdo ${ }^{5}$, L.D. Barbosa ${ }^{6}$, \\ R.D. Santos $^{4}$, G.G.L. Araújo ${ }^{4}$, L.G.N. Brandão ${ }^{7}$ \\ ${ }^{1}$ Aluno de pós-graduação - UNIVASF - Petrolina, PE - Bolsista Capes \\ ${ }^{2}$ Embrapa Gado de Leite - Juiz de Fora, MG \\ ${ }^{3}$ Universidade Federal de Lavras - Lavras, MG \\ ${ }^{4}$ Embrapa Semiárido - Petrolina, PE \\ ${ }^{5}$ UESC - Ilhéus, BA \\ ${ }^{6}$ Aluna de graduação - UNIVASF - Petrolina, PE \\ ${ }^{7}$ FTC - Feira de Santana, BA
}

\begin{abstract}
RESUMO
Avaliou-se o efeito da substituição do milho por farelo de manga em dietas para ovinos. As características avaliadas foram: consumo e digestibilidade aparente da matéria seca (MS), da proteína bruta (PB), da fibra em detergente neutro (FDN), da matéria orgânica (MO), do extrato etéreo (EE), da energia bruta (EB), da energia digestível (ED), dos carboidratos não fibrosos (CNF) e dos carboidratos totais (CT). Vinte e quatro cordeiros Santa Inês foram distribuídos em delineamento inteiramente ao acaso, com quatro tratamentos, constituídos pelas porcentagens de substituição do milho pelo farelo de manga -0 , 33, 66 e 100\% -, com seis repetições. A matéria seca fecal foi estimada utilizando-se o indicador LIPE ${ }^{\circledR}$. Não houve efeito da inclusão do farelo de manga sobre o consumo dos nutrientes e nos coeficientes de digestibilidade. Os consumos de EB e ED, em kcal/gMS, aumentaram linearmente com a inclusão do farelo de manga. $\mathrm{O}$ farelo de manga pode substituir o milho em dietas para ovinos, sem comprometer o consumo e a digestibilidade dos nutrientes, indicando a possibilidade de uso na dieta desses animais como alimento alternativo.
\end{abstract}

Palavras-chave: fruta, confinamento, consumo, coprodutos, digestibilidade

\begin{abstract}
The effect of replacing corn meal with mango meal in diets of feedlot lambs was evaluated. Apparent digestibility and intakes of dry matter $(D M)$, crude protein $(C P)$, neutral detergent fiber (NDF), organic matter $(O M)(E E)$, gross energy $(G E)$, digestible energy $(D E)$, non-fiber carbohydrates $(N F C)$ and total carbohydrates (TC) were evaluated. Twenty-four Santa Inês lambs were distributed in a randomized design with four treatments, consisting of the replacement levels of corn meal by mango (0, 33, 66 and $100 \%)$ with six replicates. The fecal dry matter was estimated using LIPE $®$ external marker. There is no effect of mango meal inclusion levels on the intake and apparent digestibility. The intakes of GE and DE in kcal/gDM increase linearly with mango meal inclusion. The mango meal can replace corn in diets for lambs without compromising the intake and digestibility of nutrients, indicating potential as an alternative feed.
\end{abstract}

Keywords: fruits, feedlot, intake, co-products, digestibility

Recebido em 15 de março de 2011

Aceito em 8 de fevereiro de 2012

E-mail: luiz.gustavo@cnpgl.embrapa.br 


\section{INTRODUÇÃO}

O sertão do Vale do São Francisco abriga efetivos de ovinos e caprinos que ocupam as primeiras posições no contexto nacional. $\mathrm{Na}$ região de sequeiro é a atividade de maior importância econômico-social. Embora possua um rebanho numericamente expressivo, a ovinocultura no semiárido é caracterizada por baixos rendimentos, devido à predominância do tipo de exploração extensiva na maioria dos criatórios, a qual sofre grande influência das condições climáticas.

A acentuada redução anual na oferta de alimentos, durante a estação de seca, é o principal fator determinante do nível de produtividade. Logo, a busca de novas alternativas de alimentos de baixo custo e de boa eficiência biológica tem sido uma necessidade e um desafio para criadores da região. A utilização de coprodutos da fruticultura na alimentação animal é uma alternativa promissora para este propósito.

Segundo estimativas da FAO (1994), nos países em desenvolvimento, as perdas pós-colheita de frutas frescas são estimadas na ordem de 20 a $50 \%$. Souza e Santos (2004) estimaram que a América Latina produz mais de 500 milhões de toneladas de resíduos, sendo o Brasil responsável por mais da metade desta produção, o que demonstra que o crescimento dos resíduos está diretamente relacionado ao aumento da produtividade agrícola.

Levando-se em consideração a quantidade produzida dentre as frutíferas cultivadas no polo Juazeiro-Petrolina, destaca-se a manga, com 359 toneladas produzidas nos municípios de Juazeiro e Petrolina no ano de 2008 IBGE (Brasil. 2010). Frequentemente, nos períodos de safra, o preço da manga atinge valores muito baixos. Os produtores muitas vezes optam pela não comercialização para evitarem os custos de colheita e transporte; assim, a utilização destes frutos na alimentação de ruminantes pode ser uma estratégia para a obtenção de produtos nobres, como a carne e o leite, e uma opção para o aumento da renda dos produtores da região.

Pereira et al. (2008), ao avaliarem o valor nutritivo do coproduto de manga por meio da técnica in vitro semiautomática de produção de gases, observaram que este coproduto tem potencial para ser utilizado na alimentação de ruminantes, entretanto são necessários estudos envolvendo a resposta animal.

Nesse contexto, o presente trabalho teve o objetivo de avaliar o consumo e a digestibilidade aparente de ovinos submetidos a porcentagens crescentes de substituição do milho moído pelo farelo do fruto da manga.

\section{MATERIAL E MÉTODOS}

O delineamento experimental utilizado foi inteiramente ao acaso, com quatro tratamentos e seis repetições. Os tratamentos constituíram-se de: capim-elefante $(\mathrm{CE})+$ concentrado padrão (farelo de soja + milho); $\mathrm{CE}+33 \%$ de farelo de manga (FM) em substituição ao milho do concentrado padrão; $\mathrm{CE}+66 \%$ de FM em substituição ao milho do concentrado padrão e $\mathrm{CE}+100 \%$ de FM em substituição ao milho (Tab. 1). O farelo de manga foi obtido de frutas integrais, sem valor comercial, que foram desintegradas em picadeira estacionária e desidratadas ao sol por 48 horas.

Tabela 1. Composição percentual dos ingredientes nas dietas (\% na MS)

\begin{tabular}{lcccc}
\hline \multirow{2}{*}{ Ingrediente } & \multicolumn{4}{c}{ Farelo de manga $(\%)$} \\
\cline { 2 - 5 } & 0 & 33 & 66 & 100 \\
\hline Capim-elefante & 40,0 & 40,0 & 40,0 & 40,0 \\
Milho & 46,9 & 31,3 & 16,0 & 0,0 \\
Farelo de manga & 0,0 & 15,2 & 30,2 & 45,7 \\
Ureia & 0,0 & 0,4 & 0,7 & 1,1 \\
Farelo de soja & 13,1 & 13,1 & 13,1 & 13,2 \\
\hline Total & 100 & 100 & 100 & 100 \\
\hline
\end{tabular}

Foram utilizados 24 ovinos machos, castrados, da raça Santa Inês, com peso médio inicial de $33,4 \pm 3,2 \mathrm{~kg}$. Inicialmente, os animais foram pesados, vermifugados e, em seguida, alojados em baias individuais providas de comedouro, bebedouro e saleiro. 
Os animais foram alimentados à vontade, duas vezes por dia, às $7 \mathrm{~h} 30 \mathrm{~min}$ e às $16 \mathrm{~h} 30 \mathrm{~min}$, com rações formuladas para serem isonitrogenadas (12\% PB na matéria seca total), sendo a relação concentrado:volumoso fixada em 60:40 (Tab. 2).
As quantidades fornecidas foram ajustadas para que as sobras correspondessem a $15 \%$ do oferecido. Água e mistura mineral foram oferecidas à vontade.

Tabela 2. Composição bromatológica do capim-elefante, do farelo de manga e das rações totais contendo farelo de manga em substituição ao milho moído

\begin{tabular}{lllllll}
\hline \multirow{2}{*}{ Item } & \multicolumn{1}{c}{$\begin{array}{c}\text { Capim- } \\
\text { elefante }\end{array}$} & $\begin{array}{c}\text { Farelo de } \\
\text { manga }\end{array}$ & & \multicolumn{4}{c}{ Farelo de manga } \\
\cline { 5 - 7 } MS, \% & 23,51 & 89,53 & 62,95 & $63 \%$ & $66 \%$ & $100 \%$ \\
MO, \% & 91,70 & 96,35 & 94,50 & 94,35 & 63,24 & 63,39 \\
MM, \% & 8,31 & 3,65 & 5,50 & 5,65 & 5,81 & 94,03 \\
PB, \% & 4,66 & 4,47 & 11,69 & 12,06 & 12,17 & 12,51 \\
FDN, \% & 78,35 & 22,86 & 44,15 & 44,67 & 45,17 & 45,71 \\
FDA, \% & 51,87 & 15,30 & 27,18 & 28,54 & 29,06 & 31,27 \\
EE, \% & 1,90 & 5,12 & 2,96 & 3,30 & 3,63 & 3,98 \\
EB, kcal/g & 2962,08 & 4456,28 & 3636,28 & 3740,76 & 3843,23 & 3951,08 \\
CNF, \% & 6,78 & 63,89 & 35,71 & 35,39 & 35,08 & 34,71 \\
CT, \% & 85,13 & 86,75 & 79,86 & 80,06 & 80,26 & 80,42 \\
\hline
\end{tabular}

MS: matéria seca; MO: matéria orgânica; MM: matéria mineral; PB: proteína bruta; FDN: fibra em detergente neutro; FDA: fibra em detergente ácido; EE: extrato etéreo; EB: energia bruta; CNF: carboidratos não fibrosos; CT: carboidratos totais.

O experimento teve duração de 21 dias, sendo 16 dias de adaptação dos animais às baias e às dietas e cinco dias de coleta de dados. Durante o período de coleta, foram quantificados diariamente o capim-elefante fornecido $\mathrm{e}$ as sobras no cocho. Os alimentos concentrados foram amostrados individualmente antes de serem misturados. A coleta de amostras de fezes foi realizada diretamente na ampola retal dos animais, e a estimativa da produção de MS fecal realizada utilizando-se como indicador a LIPE $^{\circledR}$ (1g por animal), fornecida na forma de cápsulas um dia antes da coleta de fezes e durante todo o período de coleta.

As amostras dos alimentos fornecidos, das sobras de alimentos e das fezes foram avaliadas em duplicatas, sendo determinados os teores de matéria seca (MS), matéria orgânica (MO), proteína bruta $(\mathrm{PB})$, energia bruta $(\mathrm{EB})$, extrato etéreo (EE), segundo as metodologias descritas por Silva e Queiroz (2002), e fibra em detergente neutro (FDN) e fibra em detergente ácido (FDA), segundo Van Soest et al. (1991). Os teores de carboidratos totais (CT) e carboidratos não fibrosos (CNF) foram obtidos pelas equações: $\mathrm{CT}=100-(\mathrm{PB} \%+\mathrm{EE} \%+\mathrm{MM} \%) \mathrm{e} \mathrm{CNF}=100$ $-(\mathrm{PB} \%+\mathrm{EE} \%+\mathrm{MM} \%+\mathrm{FDN} \%)$, de acordo com Sniffen et al. (1992). As análises para determinação da energia bruta foram realizadas por meio de bomba calorimétrica adiabática da marca PARR (Association... 1980).

Os valores de digestibilidade aparente dos nutrientes foram obtidos conforme recomendações de Silva e Leão (1979). Os valores de energia digestível (ED) foram obtidos pela diferença entre a energia bruta ingerida e a excretada nas fezes.

O experimento foi realizado em delineamento inteiramente ao acaso, com seis repetições. Contrastes ortogonais foram utilizados para se avaliarem os efeitos de ordem linear e quadrática dos níveis de farelo de manga em substituição ao milho. Os procedimentos estatísticos foram realizados por intermédio do programa SAEG (Sistema..., 2003), adotando-se 5\% de significância. Devido à ausência dos efeitos cúbicos e quárticos para os níveis de farelo de manga na dieta, estes foram omitidos dos resultados.

\section{RESULTADOS E DISCUSSÃO}

Não houve efeito da inclusão do farelo de manga $(\mathrm{P}>0,05)$ sobre o consumo de matéria seca (CMS), expresso em g/dia, em \% de peso vivo e em peso metabólico (Tab. 3). Ovinos que receberam dietas com milho ou manga 
apresentaram CMS semelhantes $(\mathrm{P}>0,05)$, com média igual à de 1297,01g/dia, o que indica aceitabilidade semelhante entre os dois alimentos.

Os valores encontrados no presente trabalho para CMS, em porcentagem do peso vivo, estão abaixo dos verificados por Veras et al. (2005), que substituíram o milho moído pelo farelo de palma em dietas de ovinos e encontraram valores iguais a 4,2\% PV, entretanto acima dos valores (2,9\% PV) encontrados por Souza et al. (2004), que substituíram o milho moído pela casca de café. Zeoula et al. (2003) substituíram o milho por farinha de varredura na alimentação de ovinos e encontraram valor médio de CMS expresso em peso metabólico igual a $71,8 \mathrm{~g} / \mathrm{kgPM}$, resultado inferior ao encontrado no presente trabalho.

Tabela 3. Média e coeficiente de variação do consumo de nutrientes por ovinos, em função da substituição do milho pelo farelo de manga

\begin{tabular}{|c|c|c|c|c|c|c|}
\hline \multirow{2}{*}{ Item } & \multicolumn{4}{|c|}{ Farelo de manga } & \multirow{3}{*}{$\mathrm{CV}, \%$} & \multirow{3}{*}{ Média } \\
\hline & $0 \%$ & $33 \%$ & $66 \%$ & $100 \%$ & & \\
\hline \multicolumn{5}{|c|}{ Consumo, g/dia } & & \\
\hline MS & 1394,37 & 1221,06 & 1300,63 & 1271,97 & 20,85 & 1297,01 \\
\hline $\mathrm{PB}$ & 170,51 & 155,15 & 169,28 & 170,10 & 21,10 & 166,26 \\
\hline FDN & 582,94 & 516,80 & 544,81 & 543,58 & 20,91 & 547,03 \\
\hline FDA & 360,75 & 331,47 & 365,73 & 378,38 & 21,48 & 359,08 \\
\hline MO & 1322,15 & 1156,96 & 1234,18 & 1208,09 & 20,88 & 1230,35 \\
\hline EE & 42,63 & 42,24 & 50,84 & 55,07 & 21,70 & 47,69 \\
\hline $\mathrm{CNF}$ & 526,07 & 457,05 & 498,66 & 481,69 & 21,37 & 490,87 \\
\hline $\mathrm{CT}$ & 1109,01 & 973,85 & 1046,37 & 1025,27 & 21,12 & 1038,6 \\
\hline \multicolumn{7}{|c|}{ Consumo, \% PV } \\
\hline MS & 4,10 & 3,76 & 3,85 & 3,76 & 13,87 & 3,87 \\
\hline FDN & 1,71 & 1,59 & 1,61 & 1,61 & 13,57 & 1,63 \\
\hline \multicolumn{7}{|c|}{ Consumo, $\mathrm{g} / \mathrm{kg}^{0,75}$} \\
\hline MS & 98,92 & 89,57 & 92,82 & 90,42 & 14,87 & 92,93 \\
\hline FDN & 41,36 & 37,88 & 38,86 & 38,64 & 14,69 & 39,19 \\
\hline
\end{tabular}

MS: matéria seca; PB: proteína bruta; FDN: fibra em detergente neutro; FDA: fibra em detergente ácido; EE: extrato etéreo; EB: energia bruta; CNF: carboidratos não fibrosos; CT: carboidratos totais. Não houve efeito da substituição do milho pelo farelo de manga.

Não foi verificado efeito da substituição do milho por farelo de manga $(\mathrm{P}>0,05)$ para os consumos de PB, MO, CNF e CT (Tab. 3), fato possivelmente relacionado às equivalentes porcentagens destes nutrientes na dieta, além dos semelhantes $\quad(\mathrm{P}>0,05) \quad$ CMS observados. Comportamento similar foi observado por Souza et al. (2004), em experimentos com ovinos, quando avaliaram os efeitos da substituição do milho pela casca de café sobre os consumos de MS, PB, MO CNF e CT, e por Veras et al. (2005), quando substituíram o milho por farelo de palma na dieta de ovinos

Não foi detectado efeito $(\mathrm{P}>0,05)$ da porcentagem de farelo de manga sobre os consumos diários de FDN e EE expressos em g/dia, e sobre os consumos diários de FDN expressos em \% do PV e em \% de PM.
Cavalcante et al. (2006) avaliaram o CMS em ovinos que receberam dietas contendo cinco porcentagens - 0, 20, 40, 60 e $80 \%$ - do coproduto da manga desidratado. Observaram que o CMS (g/dia) variou $(\mathrm{P}<0,01)$ de forma quadrática à inclusão e estimaram que o consumo máximo ocorreu quando a adição foi de $36,1 \%$. Relataram, ainda, que a redução no CMS se deu a partir da utilização de $40 \%$ do coproduto de manga na dieta e atribuíram este efeito depressivo à presença dos taninos.

Não houve efeito da inclusão do farelo de manga $(\mathrm{P}>0,05)$ sobre o consumo de EB e ED expressos em kcal/dia e em kcal/kg PM (Tab. 4). Os valores de consumo de EB e ED por grama de MS consumida aumentaram linearmente com a substituição do milho moído pelo farelo de manga, o que pode ser explicado pelos teores 
crescentes de EB das dietas, provocados pelos maiores valores de $\mathrm{EE}$ do farelo de manga quando comparado ao milho moído, uma vez que as gorduras são a fração do alimento que liberam maior quantidade de energia por grama de MS oxidada, além de apresentarem elevados valores de digestibilidade.

Tabela 4. Média, equação de regressão ajustada, coeficiente de determinação $\left(\mathrm{r}^{2}\right)$ e variação do consumo de energia bruta (EB) e de energia digestível (ED)

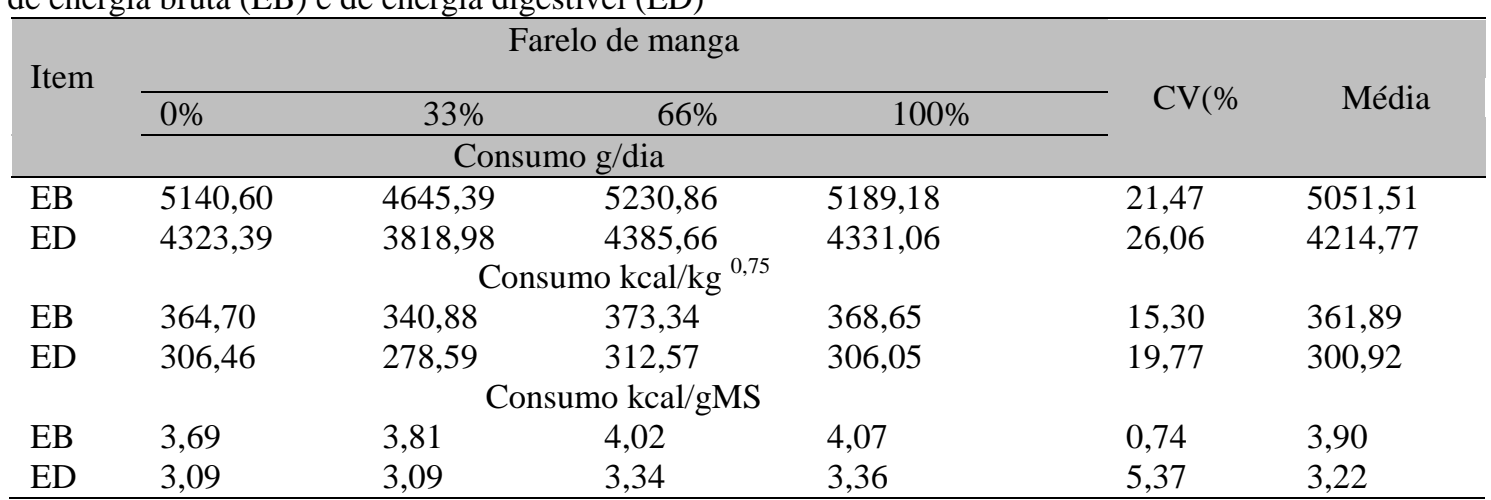

$\mathrm{Y}=3.69192+0.00412667 \mathrm{x}\left(\mathrm{r}^{2}=0,95\right)$.

$\mathrm{Y}=3.06464+0.00318838 \mathrm{x}\left(\mathrm{r}^{2}=0,83\right)$.

As digestibilidades aparentes de FDN, EE, CNF e CT não foram afetadas pela inclusão do farelo de manga. Os valores médios foram de 74,26; 83,$61 ; 88,94$ e $81,21 \%$, respectivamente (Tab. 5). Anigbogu et al. (2006), ao trabalharem com a amêndoa de manga em substituição ao milho moído, observaram que a amêndoa do caroço da manga pode substituir o milho moído em até $45 \%$, sem efeitos adversos na dieta de ovinos, entretanto os mesmos autores observaram decréscimo no consumo e na digestibilidade dos nutrientes ao aumentarem o nível de inclusão da amêndoa, de 45 para $60 \%$. Segundo esses autores, tal comportamento é atribuído às propriedades tóxicas dos compostos fenólicos presentes neste material. No presente trabalho, provavelmente devido à menor participação do caroço no farelo de manga, não houve efeito adverso dos níveis de inclusão do farelo de manga nos valores de digestibilidade aparente das dietas (Tab. 5).

Tabela 5. Coeficiente de digestibilidade dos principais nutrientes, em função dos níveis de substituição do milho pelo farelo de manga

\begin{tabular}{|c|c|c|c|c|c|c|}
\hline \multirow{2}{*}{ Item } & \multicolumn{4}{|c|}{ Farelo de manga (\% da MS) } & \multirow{2}{*}{$\mathrm{CV} \%$} & \multirow{2}{*}{ Média } \\
\hline & $0 \%$ & $33 \%$ & $66 \%$ & $100 \%$ & & \\
\hline CDMS & 81,8 & 78,1 & 79,6 & 78,5 & & \\
\hline CDPB & 77,4 & 71,5 & 75,2 & 74,2 & 6,7 & 74,6 \\
\hline CDFDN & 78,7 & 71,7 & 74,8 & 71,6 & 9,7 & 74,2 \\
\hline CDMO & 82,3 & 78,6 & 80,2 & 79,1 & 6,1 & 80,0 \\
\hline CDEE & 84,6 & 82,8 & 86,9 & 80,0 & 5,3 & 83,6 \\
\hline \multirow[t]{2}{*}{ CDCNF } & 87,9 & 89,0 & 88,7 & 90,0 & 3,6 & 88,9 \\
\hline & 83,1 & 79,9 & 81,5 & 80,2 & 6,1 & 81,2 \\
\hline
\end{tabular}

CDMS: coeficiente de digestibilidade da matéria seca; CDPB: coeficiente de digestibilidade da proteína bruta; CDFDN: coeficiente de digestibilidade da fibra em detergente neutro; CDMO: coeficiente de digestibilidade da matéria orgânica; CDEE: coeficiente de digestibilidade do extrato etéreo; CDCNF: coeficiente de digestibilidade dos carboidratos não fibrosos; CDCT: coeficiente de digestibilidade dos carboidratos totais.

De acordo com Ribeiro (2006), a quantidade de fenóis totais encontrada no coproduto de manga foi de aproximadamente $5 \%$, sendo estimada a quantidade de fenóis separadamente na casca
$(4,89 / 100 \mathrm{~g})$ e no caroço $(6,84 / 100 \mathrm{~g})$. Em altas concentrações, os compostos fenólicos contribuem para perda de cor do alimento, adstringência e sabor amargo, além de 
interagirem com proteínas, carboidratos e minerais, provocando redução do valor nutricional (Shahidi e Naczk, 1995).

Não houve efeito da inclusão do farelo de manga $(\mathrm{P}>0,05)$ sobre as digestibilidades aparentes da MS, MO e PB (Tab. 5). Os altos valores de digestibilidade da MS e MO podem ser atribuídos à relação 60:4 concentrado:volumoso das dietas, sendo o concentrado utilizado caracterizado por baixos valores de fração fibrosa e altas concentrações de CNF de elevada digestibilidade.

Correia et al. (2006), quando estudaram a digestibilidade do resíduo agroindustrial desidratado do abacaxi em caprinos utilizando o feno do capim coast cross como volumoso, obtiveram valores de coeficientes de digestibilidade da MS (71,87), MO $(73,73)$ e PB $(71,77 \%)$ inferiores aos obtidos no presente trabalho.

Lousada Júnior et al. (2005) avaliaram a digestibilidade aparente dos nutrientes em ovinos alimentados exclusivamente com subprodutos do abacaxi, da acerola, da goiaba, do maracujá e do melão. Os coeficientes de digestibilidade da MS, MO e PB do abacaxi - 47,5; 48,8 e $29 \%$-, da acerola - 22,8; 30,1 e 33,2 - da goiaba - 30,8; 30,9 e $39,5 \%$-, do maracujá - 60,0; 58,2 e $54,4 \%$-, do melão - 47,7; 45,9 e 64,8\% -, observados por esses autores, foram mais baixos que os verificados no presente trabalho. Segundo esses autores, a baixa digestibilidade apresentada em determinados subprodutos pode estar relacionada a uma possível deficiência de nutrientes nas dietas oferecidas aos animais, uma vez que as dietas consistiam exclusivamente de subprodutos.

Pereira et al. (2008), ao estudarem o valor nutricional do coproduto de manga, encontraram valores de degradabilidade da MS após 48 horas de incubação igual a $83 \%$, enquanto Valadares Filho et al. (2006) reportaram, na Tabela Brasileira de Composição de Alimentos, valor de digestibilidade in vitro da MS para o milho moído igual a $81,1 \%$. As semelhanças nos valores de digestibilidade destes dois alimentos podem estar relacionadas à similaridade $(\mathrm{P}>0,05)$ na digestibilidade dos nutrientes das dietas estudadas.
Como a substituição do milho pelo farelo de manga não alterou o consumo e o coeficiente de digestibilidade aparente das dietas, a tomada de decisão de substituição vai depender da disponibilidade e do custo do farelo de manga em relação ao milho grão.

\section{CONCLUSÕES}

O farelo de manga pode substituir o milho em até $100 \%$ em dietas de ovinos confinados, sem interferir no consumo e na digestibilidade dos nutrientes da dieta. O farelo de manga é um alimento alternativo, podendo constituir a base do concentrado energético de ovinos em confinamento.

\section{REFERÊNCIAS}

ANIGBOGU, N.M.; BIENSTMAN, P.; VAN DAMME, B. et al. Incorporation of Dry Mangifera indica Kernel in the Concentrate Ration of Growing Lambs. Rev. Elevage Med. Vet. Pays Tropicaux, v.59, p.39-42, 2006.

ASSOCIATION of official agriculture chemists AOAC. Official methods of analyses of the Association of Agriculture Chemists. 13.ed. Washington, D.C.: 1980. 1015p.

BRASIL. IBGE. Produção Agrícola Municipal 2008. Disponível em:

<http://www.sidra.ibge.gov.br/bda/pesquisas/pam/defa ult.asp>. Acessado em: jan. 2010.

CAVALCANTE, M.A.; CLEMENTINO, R.H.; NEIVA, J.N. et al. Consumo e digestibilidade da matéria seca de dietas contendo diferentes níveis de subproduto da manga. In: REUNIÃO ANUAL DA SOCIEDADE BRASILEIRA DE ZOOTECNIA, 43., 2006, João Pessoa. Anais... João Pessoa - PB: Sociedade Brasileira de Zootecnia, 2006. CD ROM.

CORREIA, M.X.C.; COSTA, R.G.; SILVA, J.H.V. et al. Utilização de resíduo agroindustrial de abacaxi desidratado em dietas para caprinos em crescimento: digestibilidade e desempenho. Rev. Bras. Zootec., v.35, p.1822-1828, 2006.

FAO. Production Yearbook. Roma. V.48, p.164-165. (FAO Statistcs, 125). 1994.

LOUSADA JÚNIOR, J.E.; NEIVA, J.N.; RODRIGUEZ, N.M. et al. Consumo e de subprodutos do processamento de frutas em ovinos. Rev. Bras. Zootec., v.34, p.659-669, 2005.

PEREIRA, L.G.R.; BARREIROS, D.C.; OLIVEIRA L.S. et al. Composição química e cinética de fermentação ruminal de subprodutos de frutas no sul da Bahia. Liv. Res. Rural Devel., v.20, p.1, 2008. 
RIBEIRO, S.M.S. Caracterização e avaliação do potencial antioxidante de mangas (Mangifera indica L.) cultivadas no estado de Minas Gerais. 2006. 149f. Tese (Doutorado em Bioquímica Agrícola) Universidade Federal de Viçosa, Viçosa, MG.

SHAHIDI, F.; NACZK, M.F. Food phenolcs: sources, chemitrys, effects and applications. Lancaster. Technomic, 1995, 331p.

SILVA, J.F.C., LEÃO, M.I. Fundamentos de nutrição dos ruminantes. Piracicaba: Livroceres, 1979. 380p.

SILVA, D.J.; QUEIROZ, A.C. Análise de alimentos: métodos químicos e biológicos. 3.ed. Viçosa: UFV, 2002. 235p.

SISTEMA para análises estatísticas. SAEG. Versão 8.1, Viçosa:UFV, 2003. 301 p.

SNIFFEN, C.J.; O'CONNOR, J.D.; Van SOEST, P.J. et al. A net carbohydrate and protein system for evaluating cattle diets: II. Carbohydrate and protein availability. J. Anim. Scie., v.70, p.3562-3577, 1992.

SOUZA, A.L.; GARCIA, R.; BERNARDINO, F.S. et al. Casca de café em dietas de carneiros: consumo e digestibilidade. Rev. Bras. Zootec., v.33, p.2170-2176, 2004.
SOUZA, O.E.; SANTOS, E.I. Aproveitamento de resíduos e subprodutos agropecuários pelos ruminantes. 2004. Disponível em: $<$ www.cpatc.embrapa.br/index.php?idpagina $=$ artigos $\&$ artigo=914>. Acessado em: dez. 2009.

VALADARES FILHO, S.C.; MAGALHÃES, K.A.; ROCHA Jr., V.R.; CAPPELLE, E.R. Tabelas brasileiras de composição de alimentos para bovinos. CQBAL 2.0. Viçosa, MG: Universidade Federal de Viçosa, 2006. 297p

VAN SOEST, P.J.; ROBERTSON, J.B.; LEWIS, B.A. Methods for extraction fiber, neutral detergent fiber and non-starch polysaccarides in relation to animal nutrition cows. J. Dairy Sci., v.74, p.3583-3597, 1991.

VERAS, R.M.; FERREIRA, M.A.; CAVALCANTI, C.V.A. et al. Substituição do milho por farelo de palma forrageira em dietas de ovinos em crescimento: desempenho. Rev. Bras. Zootec., v.34, p.249-256, 2005.

ZEOULA, L.M.; CALDAS NETO, S.F.; GERON, L.J.V. et al. Substituição do milho pela farinha de varredura de mandioca (Manihot esculenta Crantz) em rações de ovinos: consumo, digestibilidade, balanços de nitrogênio e energia e parâmetros ruminais. Rev. Bras. Zootec., v.32, p.491-502, 2003. 